\title{
Epicardial Mapping of Sustained Ventricular Tachycardia in Nonischemic Heart Disease
}

\author{
Geórgia Guedes da Silva, Henrique Horta Veloso, Luiz Roberto Leite, Roberto Lima Farias, Angelo Amato \\ Vincenzo de Paola \\ Escola Paulista de Medicina - UNIFESP, São Paulo, SP - Brazil
}

\begin{abstract}
Background: The complexity of reentrant circuits related to ventricular tachycardias decreases the success rate of radiofrequency ablation procedures.
\end{abstract}

Objective: To evaluate whether the epicardial mapping with multiple electrodes carried out simultaneously with the endocardial mapping helps in ablation procedures of sustained ventricular tachycardia (VT) in patients with nonischemic heart disease.

Methods: Twenty-six patients with recurrent sustained VT, of which $22(84.6 \%)$ presenting chronic chagasic cardiomyopathy, $2(7.7 \%)$ with idiopathic dilated cardiomyopathy and 2 with right ventricular arrhythmogenic dysplasia (RVAD), were submitted to epicardial mapping with two or three microcatheters, with 8 electrodes each, simultaneously to the conventional endocardial mapping. A catheter with a 4-mm tip was used for the ablation by radiofrequency (RF) carried out during the induced VT.

Results: Of the 33 induced VT, 25 were mapped and 20 had their origin defined. Eleven had epicardial and 9 had endocardial origin. The programmed ventricular stimulation did not induce sustained VT in 11 (42.0\%) of the 26 patients after the ablation. Events such as VT recurrence and death occurred in $\mathbf{1 0 . 0 \%}$ of the patients submitted to successful ablation and in $59.0 \%$ of the unsuccessful cases, during a mean ambulatory follow-up of $357 \pm 208$ days.

Conclusion: Subepicardial circuits are frequent in patients with nonischemic heart disease. The epicardial mapping with multiple catheters carried out simultaneously with the endocardial mapping contributes to the identification of these circuits in a same procedure. (Arq Bras Cardiol 2011; 96(2): 114-120)

Keywords: Tachycardia, ventricular; heart diseases; arrhythmias, cardiac; catheter ablation.

\section{Introduction}

Ventricular arrhythmias are frequent in nonischemic cardiomyopathies, with sustained ventricular tachycardia (VT) being common in up to $60 \%$ of the patients submitted to Holter monitorization ${ }^{1-3}$. When compared to patients without sustained arrhythmia, the sustained VT is related to a higher degree of myocardial fibrosis and affects both subendocardial and subepicardial fibers ${ }^{4,5}$.

The success rates of ablation by radiofrequency (RF) are lower in these types of cardiopathy when compared to those obtained with the ischemic type, ranging from $25 \%$ to $60 \%{ }^{6-}$ ${ }^{11}$. With the objective of attaining better results, epicardial mapping techniques have been developed, with access through the coronary vessels $\mathrm{s}^{12}$ and by percutaneous puncture of the pericardial space ${ }^{13}$. The hypothesis of the present study

Mailing address: Georgia Guedes da Silva •

Rua Alves Guimarães, 960/12 - Pinheiros - 05410-001 - São Paulo, SP - Brazil E-mail: georgia_guedes@uol.com.br

Manuscript received September 27, 2009; revised manuscript received July 12, 2010; accepted July 16, 2010. was that when the epicardial and endocardial mapping are performed simultaneously during sustained VT, it would allow a higher number of circuits to be identified and ablated.

\section{Methods}

The present was a longitudinal study with retrospective analysis, involving 26 patients with sustained VT and nonischemic cardiopathy. The study was approved by the Ethics Committee in Research of Hospital São Paulo Universidade Federal de São Paulo. All patients signed the Free and Informed Consent Form. Consecutive patients with nonischemic cardiopathy and recurrent sustained VT, who presented hemodynamic tolerance during tachycardia and were refractory to conventional drug treatment, were considered eligible for the study. Patients who did not present hemodynamic tolerance during tachycardia, those with a previous history of heart surgery, pericardial pathology, severe chronic diseases, as well as pregnant patients, were excluded from the study.

The electrophysiological study was carried out in patients under general anesthesia. Initially, an angiographic catheter 
was inserted into the right ventricle (RV), via femoral venous route. Subsequently, a subxiphoid puncture was performed in order to reach the pericardial space. A manual contrast injection into the RV was performed during this puncture, in order to attain better visualization of the RV boundaries. The puncture and posterior introduction of a guidewire in the pericardial space were carried out in the left anterior oblique view.

A standard $8 \mathrm{~F}$ introducer sheath or long sheath was inserted into the pericardial space and based on the electrocardiographic recordings of the clinical VT, two or three 3,3 F octopolar microcatheters, with 3-mm electrodes and inter-electrode spaces of $2 \mathrm{~mm}$ (Revelation ${ }^{\mathrm{TM}}$, Cardima, Freemont, California, USA), were positioned in the areas of interest. The conventional endocardial catheters were introduced through the right femoral vein and artery for ventricular stimulation, mapping and ablation. A bolus of $5,000 \mathrm{UI}$ of heparin, via IV route, was administered after all punctures, followed by 1,000 UI per hour.

Three body surface electrodes, DI, avf and $\mathrm{V} 1$, the intracavitary electrograms of the right ventricle (RV) and left ventricle (LV), in addition to the 16 epicardial electrodes of the microcatheters, were recorded during the procedure by the BARD (Electrophysiology-Labsystem-version 2.97) or TEB (Tecnologia Eletrônica Brasileira) polygraphs. The bipolar recordings were filtered from 100 to $500 \mathrm{~Hz}$ at velocities of 25, 100 and $200 \mathrm{~mm} / \mathrm{s}$. The programmed ventricular stimulation was carried out with two cycles (600 and $450 \mathrm{~ms}$ ) and with up to three extrastimuli, at the right ventricular apex and outflow tract. The epicardial microcatheters and the endocardial catheter were placed in all patients before the start of the mapping (Figure 1).

If the electrograms recorded by the microcatheters suggested epicardial origin, the endocardial catheter was placed on the endocardial region closest to the highest presystolic activity recorded by the epicardial microcatheters (at least $30 \mathrm{~ms}$ ).

If the mapping suggested an epicardial circuit, the microcatheters were removed and a 4-mm conventional 7 or $8 \mathrm{~F}$ quadripolar catheter was placed in the pericardial space, for ablation. In the presence of endocardial circuits, the strategy of simultaneous mapping was similar and conventional techniques of endocardial ablation were used. The circuits were defined as having epicardial location when, after juxtaposition of the endocardial and epicardial catheters, the presence of mesodiastolic potentials or earlier pres-systolic activity was observed on this surface, with entrainment compatible with location in the protected isthmus of the reentry circuit.

The coronary angiography was carried out before the use of RF on the epicardial surface in order to prevent coronary artery injury. The distance between the catheter and the coronary artery was measured using the Cardiovascular Measurement System program, release 3.0 (Medical Imaging Systems, Neunem, The Netherlands). When the distance between the coronary artery and the distal electrode of the ablation catheter was $<10 \mathrm{~mm}$, the RF was not applied.

The maximum power during RF use was 50 watts, limited by a maximum temperature of $60^{\circ} \mathrm{C}$ (EP Technologies Radiofrequency). If the VT was interrupted during the first 20 seconds, the RF was prolonged for 60 minutes. A successful ablation procedure was defined by the non-induction of VT, using the complete protocol of stimulation, with two cycles of frequency and up to three extrastimuli.

The patients remained in the cardiac intensive care unit for 24 hours and a transthoracic echocardiogram was performed after the procedure.

All patients were discharged from the hospital receiving amiodarone and were followed through sporadic ambulatory consultations after 7 days, 30 days, and then every three months, in order to assess the occurrence of sudden death, VT recurrence and complications related to the procedure.

The statistical analysis was carried out through SPSS 8.0.1 ${ }^{\mathrm{TM}}$ software package for Windows ${ }^{\mathrm{TM}}$. Variables were compared between the groups by Student's $t$ test (Gosset). The comparison between the groups involving continuous variables with non-parametric distribution was carried out by Mann-Whitney test for independent variables. When there was a difference between proportions, Chi-square test
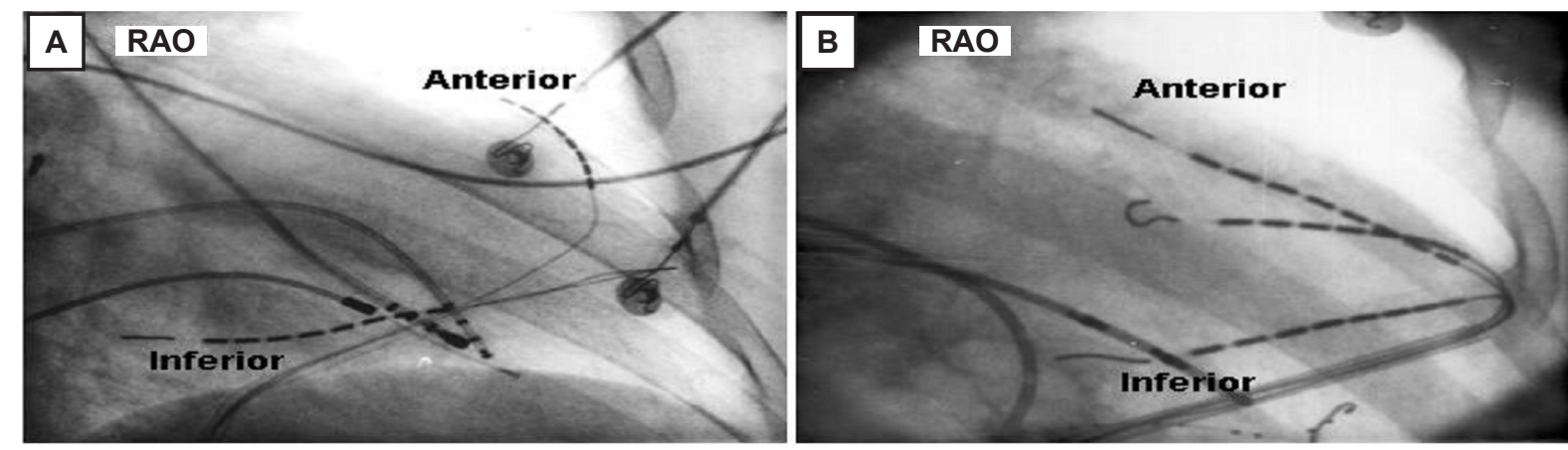

Figure 1 - Simultaneous endocardial and epicardial mapping, using two and three microcatheters in the anterior and inferior regions. A: octopolar microcatheters located in the anterior and inferior regions of the epicardial surface and endocardial catheters located in the right and left ventricles; B: octopolar microcatheters on the epicardial surface, with one of them located in the left ventricular apex. 


\section{Original Article}

or Fisher's exact test were used. All tests were two-tailed and the probability of significance $(p)$ used was $<0.05$ to reject the null hypothesis.

The present study was carried out with financial support from Conselho Nacional de Desenvolvimento Científico e Tecnológico - CNPq.

\section{Results}

Of the 26 patients studied, 22 (84.6\%) presented chronic chagasic cardiopathy, two (7.7\%) presented idiopathic dilated cardiomyopathy and two (7.7\%) presented RV arrhythmogenic dysplasia. The left ventricular ejection fraction (LVEF) varied from $27.0 \%$ to $79.0 \%$, with a mean of $45.0 \% \pm 12.0 \%$ at the echocardiogram. Segmental dysfunction in the LV was identified in 15 patients $(57.7 \%)$, of which 1 presented dilated cardiomyopathy and 14 presented chronic chagasic cardiopathy. Eight patients presented segmental dysfunction $(30.8 \%)$ in the inferolateral region, $4(15.4 \%)$ in the mid- inferior region and three (11.5\%) in the anteroapical segment. Eight patients (31.0\%) were-se New York Heart Association (NYHA) functional class I and 18 (69.0\%) NYHA functional class II. Six patients $(23.0 \%)$ recovered from cardiac arrest. Three patients $(11.5 \%)$ had an implantable cardioverterdefibrillator. All of them used amiodarone, at a dose varying from 200 to $600 \mathrm{mg} /$ day, mean of $400 \mathrm{mg} /$ day (Table 1).

Of the 33 sustained tachycardias induced by programmed ventricular stimulation, 25 could be mapped and the site of origin was clearly defined in 20 . Of these, 11 (55.0\%) had epicardial location and 9 (45.0\%) had endocardial location. Six patients had only one tachycardia of endocardial origin and one patient had two endocardial VT. Ten patients presented epicardial VT and one patient presented one epicardial and another endocardial VT. The site of origin could not be identified in $8 \mathrm{VT}$, even after thorough mapping. In the other $5 \mathrm{VT}$, the location was not possible due to the presence of hemodynamic instability soon after the sustained VT was induced. Eighteen changes in morphology occurred

Table 1 - Clinical characteristics of patients included in the study

\begin{tabular}{|c|c|c|c|c|c|c|c|c|}
\hline $\mathrm{Pt}$ & Sex & Age & Cardiopathy & LV ejection fraction & $\begin{array}{c}\text { Funtional class } \\
\text { (NYHA) }\end{array}$ & Sudden death & $I C D$ & Amiodarone dose \\
\hline 1 & $\mathrm{~F}$ & 62 & Chagasic & $53.0 \%$ & ॥ & no & no & $400 \mathrm{mg} / \mathrm{dia}$ \\
\hline 2 & $M$ & 41 & Chagasic & $41.0 \%$ & I & no & no & $400 \mathrm{mg} / \mathrm{dia}$ \\
\hline 3 & M & 61 & Chagasic & $27.0 \%$ & II & no & no & $600 \mathrm{mg} / \mathrm{dia}$ \\
\hline 4 & $\mathrm{~F}$ & 48 & Chagasic & $79.0 \%$ & I & no & no & 400 mg/day \\
\hline 5 & $\mathrm{~F}$ & 67 & Chagasic & $35.0 \%$ & II & yes & no & 400 mg/day \\
\hline 6 & M & 48 & Chagasic & $45.0 \%$ & ॥ & yes & no & 400 mg/day \\
\hline 7 & $\mathrm{~F}$ & 56 & Chagasic & $40.0 \%$ & I & no & no & 400 mg/day \\
\hline 8 & $M$ & 52 & Chagasic & $50.0 \%$ & ॥ & no & no & 200 mg/day \\
\hline 9 & M & 61 & Chagasic & $50.0 \%$ & II & no & no & 400 mg/day \\
\hline 11 & $\mathrm{~F}$ & 73 & Chagasic & $40.0 \%$ & ॥ & yes & no & 400 mg/day \\
\hline 12 & $\mathrm{~F}$ & 60 & Chagasic & $35.0 \%$ & II & no & yes & 400 mg/day \\
\hline 13 & $\mathrm{~F}$ & 54 & Chagasic & $40.0 \%$ & $\|$ & no & no & 400 mg/day \\
\hline 14 & $M$ & 48 & Dysplasia & $60.0 \%$ & I & no & no & 400 mg/day \\
\hline 15 & M & 63 & Chagasic & $30.0 \%$ & II & no & yes & $600 \mathrm{mg} / \mathrm{day}$ \\
\hline 16 & $\mathrm{~F}$ & 63 & Chagasic & $47.0 \%$ & ॥ & no & no & 400 mg/day \\
\hline 17 & $\mathrm{~F}$ & 60 & Chagasic & $40.0 \%$ & ॥ & no & no & 400 mg/day \\
\hline 18 & $\mathrm{~F}$ & 50 & Chagasic & $38.0 \%$ & II & yes & no & 400 mg/day \\
\hline 19 & M & 50 & Dilated & $47.0 \%$ & 1 & no & no & 200 mg/day \\
\hline 20 & $\mathrm{~F}$ & 45 & Chagasic & $63.0 \%$ & II & no & no & 400 mg/day \\
\hline 23 & $\mathrm{~F}$ & 64 & Chagasic & $45.0 \%$ & II & yes & no & 400 mg/day \\
\hline 24 & $M$ & 46 & Chagasic & $45.0 \%$ & 1 & no & no & 400 mg/day \\
\hline 25 & $\mathrm{~F}$ & 41 & Dysplasia & $60.0 \%$ & I & no & no & $400 \mathrm{mg} / \mathrm{day}$ \\
\hline 26 & M & 53 & Dilated & $50.0 \%$ & I & no & no & 400 mg/day \\
\hline
\end{tabular}

Pt - patient; LV - left ventricle; ICD - implantable cardioverter-defibrillator. 
spontaneously in 10 patients during the simultaneous endocardial and epicardial mapping. Only in 4 (22.0\%) of these changes, an inversion in the sequence of ventricular activation was observed. In three of these changes, there was an inversion in the sequence pattern from epiendocardial to endoepicardial and in the fourth, the opposite occurred.

RF was successfully applied in $9(82.0 \%)$ of the 11 tachycardias located on the epicardial surface and in only 4 $(44.0 \%)$ of the 9 tachycardias with endocardial location. Of the 9 tachycardias located on the epicardial surface, three of them were in the RV, two in the RV outflow tract region (Figure 2) and one in the inferior wall. Of those located in the LV, 6 were located in the inferolateral region, one in the inferoapical region and one in the anteroapical region. Of the 8 tachycardias located in the LV, 7 were successfully aborted
( 5 in the inferolateral region, one in the inferoapical region, one in the anteroapical wall). Of 3 located in the RV, two were successfully aborted, both located in the RV outflow tract.

In two patients, after the coronary angiography was performed, the arrhythmia site was seen to be close to an important coronary branch (one in the RV inferior wall and another in the LV anterior wall), preventing the use of RF (Figure 3). In two other procedures, two different circuits were successfully treated in a same patient: one patient presented two endocardial circuits (in the anteroapical and inferolateral walls) and in the other, an endocardial circuit in the anterior wall and an epicardial circuit in the inferolateral wall were documented. In 6 patients, a pre-systolic activity of at least $40 \mathrm{~ms}$ was observed during the epicardial mapping with the octopolar microcatheters, recorded in three or four
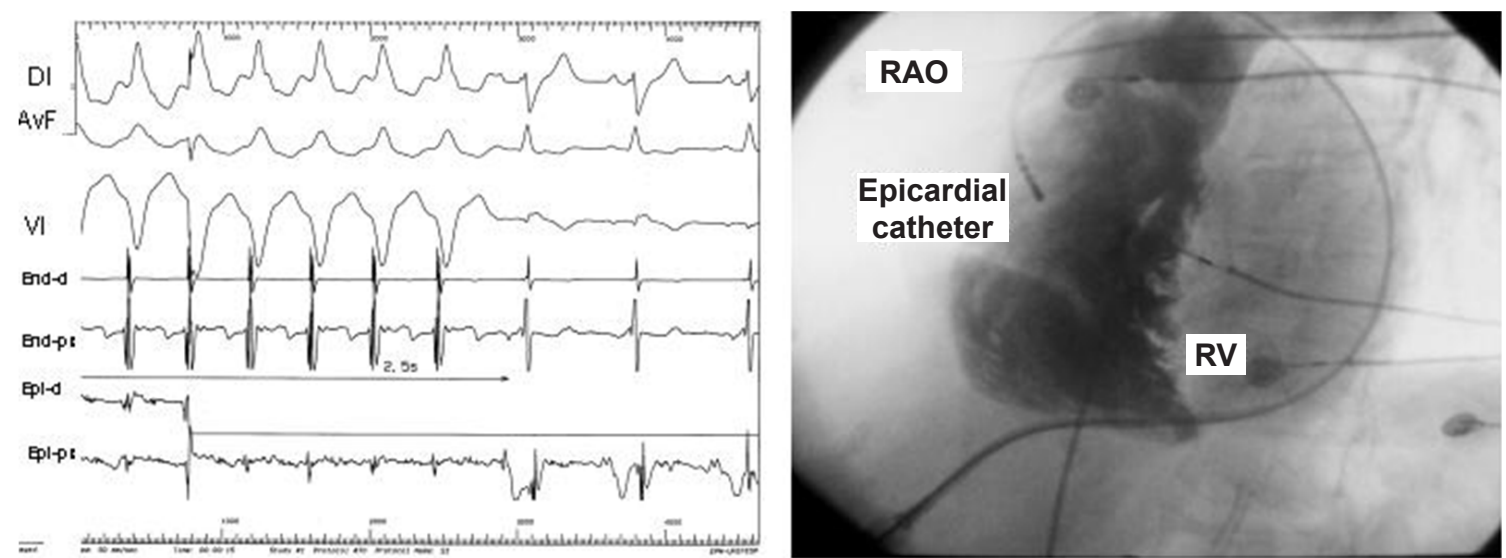

Figure 2 - Mesodiastolic potentials recorded during sustained ventricular tachycardia in the right ventricle (RV). The epicardial use of radiofrequency in the right ventricular outflow tract was successful in permanently interrupting the tachycardia. End d and End p distal and proximal endocardial catheters; Epi d and Epi p - distal and proximal epicardial catheters.
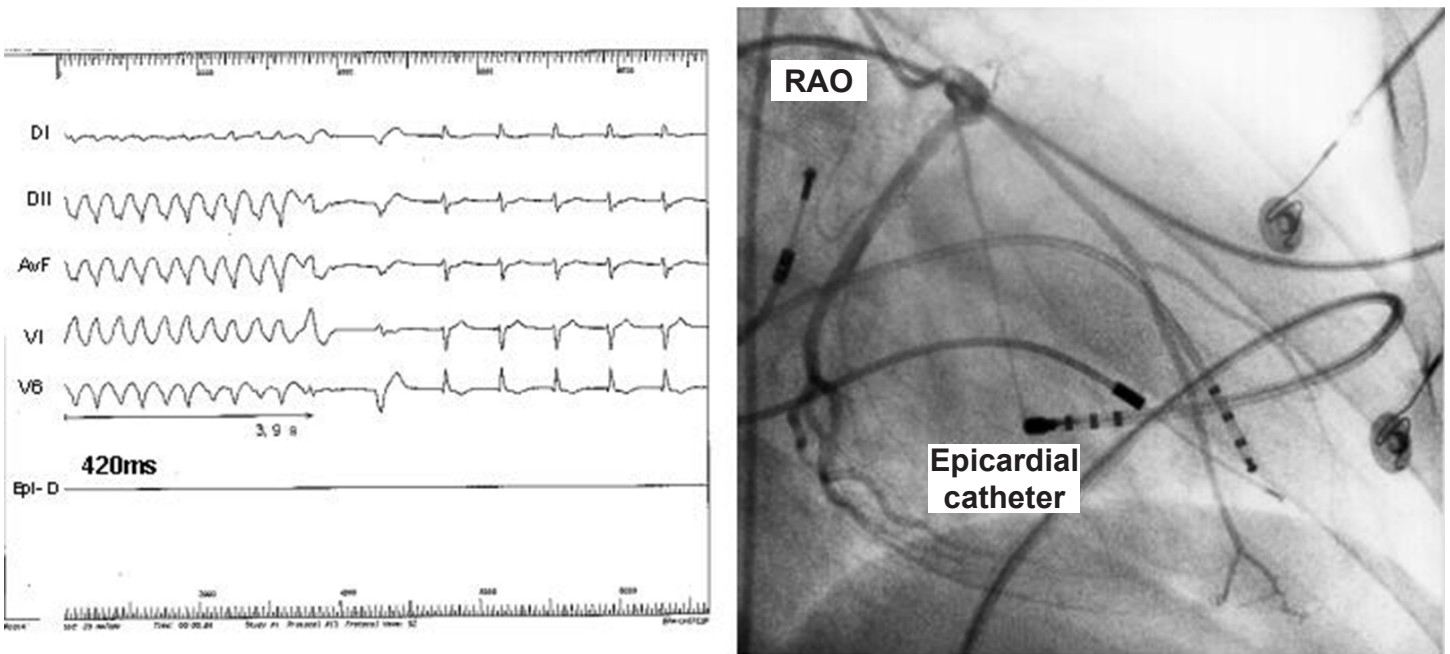

Figure 3 - Coronary angiography of the right anterior oblique (RAO) artery, showing the ablation catheter in a region distant from the most important coronary branches. Radiofrequency was used and sinus rhythm was restored after 3.9 seconds after the session was started. 


\section{Original Article}

sequential pairs of electrodes, reaching a larger extension than $3 \mathrm{~cm}$ (Figure 4). The use of RF was successfully carried out in these cases.

The mean power, impedance and temperature during the endocardial use of RF did not differ from the epicardial use $\left(20.5 \pm 13.2\right.$ watts, $90.3 \pm 14.6 \Omega, 54.3 \pm 7.5^{\circ} \mathrm{C}$ and $22, .7$ \pm 10.4 watts, $119.4 \pm 71.4 \Omega, 54.7 \pm 6.0^{\circ} \mathrm{C}$, respectively).

Immediate success was obtained with 11 of the 26 patients (42.0\%, $95 \mathrm{Cl} \%: 22.0 \%$ to $63.0 \%$ ) and in 13 of the 25 induced and mappable tachycardias (52.0\%, $95 \% \mathrm{Cl}: 27.0 \%$ to $66.0 \%)$, which became $39.0 \%$ (13 of 33 tachycardias) when evaluating all induced tachycardias and not only the mappable ones. Nine circuits (32.0\%) were treated by epicardial ablation and $4(14.0 \%)$ by endocardial approach. The pre-systolic activity was observed in 7 of the epicardial sites treated successfully, with a mean duration of $95 \pm 24 \mathrm{~ms}$ (64 to $134 \mathrm{~ms}$ ). Three treated endocardial sites presented pre-systolic activity with a mean duration of $97 \pm 19 \mathrm{~ms}$ (80 to $118 \mathrm{~ms}$ ). Mesodiastolic potentials validated by entraining technique were present in two epicardial circuits and one endocardial circuit.

One patient presented hemopericardium soon after the pericardial puncture, with no signs of cardiac tamponade, followed by immediate draining, which did not prevent the epicardial mapping to be concluded. In another procedure, the patient developed a picture of acute arterial embolism to the distal region of the right lower limb, which was solved by embolectomy, through a Fogarty catheter.

The patients were followed by a mean of $357 \pm 208$ days (30 to 208 days). Seven (22.0\%) patients died: three due to congestive heart failure, two due to complications related to heart transplant and two due to sudden death. Of the 11 patients submitted to successful ablation, 10 (90.9\%) did not present arrhythmia recurrence and one (9.1\%) died due to sudden death two years after the procedure.

Of the 15 patients with induced VT at the end of the procedure $7(46.7 \%)$ did not present VT recurrence and 5 patients died. Thus, the frequency of events in patients who were successfully submitted to ablation was significantly lower than in the patients who were not successfully treated by ablation [1/11 (9.1\%) vs 8/15 (53.3\%), p < 0.05].

\section{Discussion}

The present study investigated the importance of the simultaneous epicardial and endocardial mapping of sustained VT in patients with nonischemic cardiopathy, and particularly, the role of the use of multiple microcatheters on the epicardial surface as an adjuvant mapping technique. We observed that such strategy allowed a broad recording of the potentials generated on that surface, allowing a more accurate mapping and helping in the fast identification of extensive areas with fractionated electrograms and with pressystolic activity, arrhythmogenic substrate for VT. Soejima et $\mathrm{al}^{8}$ and Cano et $\mathrm{al}^{14}$, using electroanatomical mapping in patients with dilated cardiopathy of nonischemic etiology, observed that the circuits were more extensive on the epicardial surface, when compared with the endocardial ones. Garcia et al observed a very similar finding in RV arrhythmogenic dysplasia ${ }^{15}$ and, more recently, Henz et al ${ }^{16}$ observed the same in chagasic patients.

In our study, we observed a change in the sequence of ventricular activation during the change in morphology of

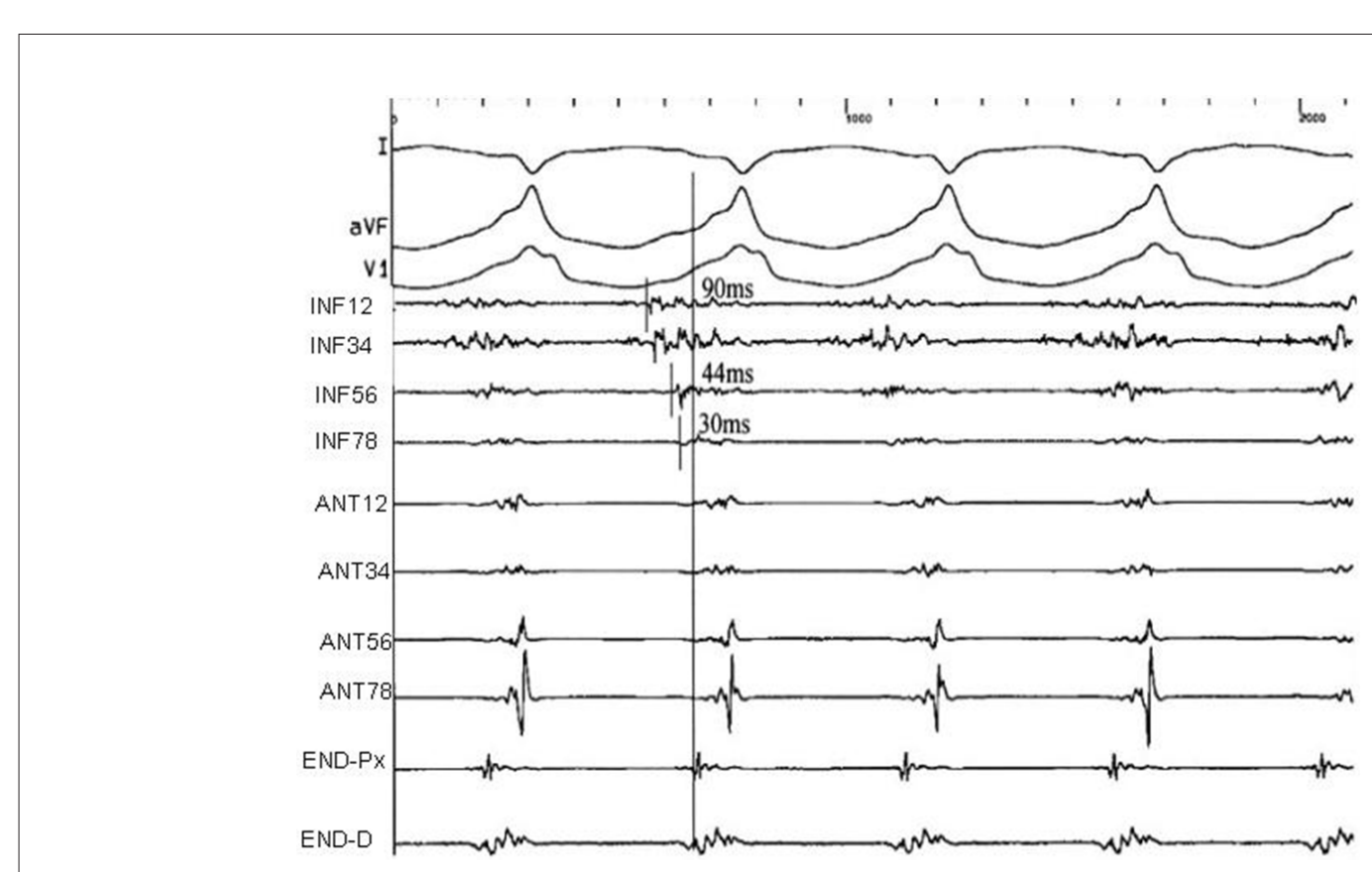

Figure 4 - Surface ECG tracings (DI, avf, V1) of microcatheters on inferior (INF 1-2, INF 3-4, INF 5-6, INF 7-8) and anterior (ANT 1-2, ANT 3-4, ANT 5-6, ANT 7-8) epicardial surfaces and distal and proximal endocardial recordings (END-D and END-PX). The octapolar microcatheters recorded an extensive area of pre-systolic activity on the inferior wall, suggesting the presence of broad epicardial circuits. 
the tachycardias. Significant alterations in the sequence of activation occurred in only $22 \%$ of the 18 changes in morphology of the QRS. Studies of changes in morphology of tachycardias have been carried out in humans only during surgical procedures in patients post-acute myocardial infarction and with tachycardias of endocardial origin ${ }^{17-21}$.

The studies that evaluated the multiple morphologies, but in general not the moment of spontaneous change of the QRS complex, used intraoperative mapping techniques with several electrodes recording the endocardial and epicardial activity ${ }^{17-28}$. In the present study, carried out in patients with nonischemic cardiopathy, most of the changes in morphology were not associated with the inversion in the sequence of activation, with slight alterations regarding the site with higher or lower pres-systolic activity. Our finding might suggest that the morphological change mechanisms occur only on the surface of the tachycardia origin. We acknowledge that, in spite of this characteristic occurred in $88.0 \%$ of the changes in morphology, it is not possible to know what occurred at the deeper layers of the myocardium, using only catheters on the endocardial and epicardial surfaces.

When evaluating the incidence of epicardial and endocardial circuits and considering only those that could be successfully approached and modified, the incidence of epicardial circuits was higher, when compared with the endocardial ones.

In two cases, on the epicardial surface, in spite of the validation as a good location for the use of the RF, the latter could not be performed due to the proximity of important coronary vessels.

Therefore, there was arrhythmia interruption in all circuits located on the epicardial surface to which RF was applied, without VT re-induction.

On the other hand, on endocardial surface, in spite of the location of good electrograms and adequate validation, 5 of the tachycardias could not be interrupted, after several attempts to apply the RF. The lack of success when applying the RF in 5 of the $9 \mathrm{VT}$ of supposedly endocardial origin might be related to the participation of transmural fibers, which are difficult to approach through conventional ablation catheters used in our study, thus justifying the use of catheters with an irrigated tip in this condition ${ }^{16}$.

It would be interesting to discuss that the higher capacity for successful approach in epicardial circuits might be related to their higher incidence and a smaller transmural trajectory participating in these circuits, which would favor the easier identification and therapeutic resolution when using conventional catheters. However, the absence of a control group does not allow us to adequately assess these data.

The rate of complications during the mapping was $7.6 \%$, two events, which were completely solved in 26 studied patients. The arterial embolism occurred toward the digital portion of the right lower limb, clearly related with the femoral artery puncture. The hemopericardium was identified due to the constant observation of the heart border excursion at the radioscopy and blood aspiration by the sheath located in the pericardial space, even before the patient presented signs of cardiac tamponade. Considering that both complications were nonfatal and easily and completely resolved, we consider the described method of mapping to be safe.

The simultaneous endocardial and epicardial mapping during the sustained VT is a technique with limitations related to the presentation of the sustained VT, such as hemodynamic tolerance, number of circuits, number of morphologies and difficulty to maintain the tachycardia.

The number of patients in our study does not allow us to perform an adequate assessment regarding the impact on mortality after the therapeutic use of RF. However, when we analyze the recurrence of arrhythmia, $90.0 \%$ of the patients submitted to the successful ablation by RF did not present a new episode of VT during the follow-up. In spite of the elevated rate of mortality observed (28.0\%), the deaths were not directly related with the arrhythmias.

\section{Conclusions}

Sub-epicardial circuits are frequent in patients with nonischemic cardiopathy. The epicardial mapping with multiple catheters, when performed simultaneously with the endocardial mapping, contributes to the identification of these circuits in the same procedure.

The extensive area of pres-systolic activity recorded by the microcatheters on the epicardial surface and the minimal alterations in the sequence of pre-systolic activity during the spontaneous changes in morphology might be related with particularities of the macro-reentrant circuits of nonischemic cardiopathies, which are yet to be defined.

\section{Potential Conflict of Interest}

No potential conflict of interest relevant to this article was reported.

\section{Sources of Funding}

This study was funded by CNPq.

\section{Study Association}

This article is part of the thesis of doctoral submitted by Geórgia Guedes da Silva, from Escola Paulista de Medicina - Unifesp. 


\section{Original Article}

\section{References}

1. Huang SK, Messer JV, Denes P. Significance of ventricular tachycardia in idiopathic dilated cardiomyopathy. Am J Cardiol. 1983; 51 (3): 507-12.

2. Meinertz T, Hofmann T, Kasper W, Treese N, Bechtold H, Stienen U, et al. Significance of ventricular arrhythmias in idiopathic dilated cardiomyopathy. Am J Cardiol. 1984; 53 (7): 902-7.

3. Von Olshausen K, Schafer A, Mehmel H. Ventricular arrhythmias in idiopathic dilated cardiomyopathy. Br Heart J. 1984; 51 (2): 195-201.

4. Hsia HH, Marchlinski FE. Electrophysiology studies in patients with dilated cardiomyopathies. Card Electrophysiol Rev. 2002; 6 (4): 472-81.

5. Pelliccia F, Critelli G, Cianfrocca C, Nigri A, Reale A. Electrocardiographic correlates with left ventricular morphology in idiopathic dilated cardiomyopathy. Am J Cardiol. 1991; 68 (6): 642-7.

6. Coyne RF, Marchlinski FE. Ablation of ventricular tachycardia associated with non ischemic structural heart disease. In: Huang SS. Radiofrequency catheter ablation of cardiac arrhythmias: basic concepts and clinical application. Armonk (New York): Futura Publishing Company Inc; 2000. p. 705-35.

7. Delacretaz E, Stevenson WG, Ellison KE, Maisel WH, Friedman PL. Mapping and radiofrequency catheter ablation of the three types of sustained monomorphic ventricular tachycardia in nonischemic heart disease. J Cardiovasc Electrophysiol. 2000; 11 (1): 11-7.

8. Soejima K, Stevenson WG, Sapp JL, Selwyn AP, Couper G, Epstein LM. Endocardial and epicardial radiofrequency ablation of ventricular tachycardia associated with dilated cardiomyopathy: the importance of low-voltage scars. J Am Coll Cardiol. 2004; 43 (10): 1834-42.

9. Sosa EA, Scalabrini A, Rati M, Bellotti G, Pileggi F. Successful catheter ablation of the origin of recurrent ventricular tachycardia in chronic chagasic heart disease. J Cardiovasc Electrophysiol. 1987; 1 (1): 58-61.

10. Sosa EA, Scanavacca M, Martinelli Filho M, Lee JH, Rati M, Bellotti G, et al. Técnicas de ablação por cateter (fulguração): experiência inicial. Arq Bras Cardiol. 1988; 50 (4): 253-8.

11. Tavora MZP, Metha N, Silva RMFL, Godim FA, Hara VM, Paola AV. Características e identificação dos sítios de taquicardia ventricular de etiologia chagásica por mapeamento endocárdico. Arq Bras Cardiol. 1999; 72 (4): 463-74.

12. Stellbrink C, Diem B, Schauerte P, Ziegert K, Hanrath P. Transcoronary venous radiofrequency catheter ablation of ventricular tachycardia. J Cardiovasc Electrophysiol. 1997; 8 (8): 916-21.

13. Sosa E, Scanavacca MI, D'Ávila A, Pilleggi F. A new technique to perform epicardial mapping in the electrophysiology laboratory. J Cardiovasc Electrophysiol. 1996; 7 (6): 531-6.

14. Cano O, Hutchinson M, Lin D, Garcia F, Zado E, Bala R, et al. Electroanatomic substrate and ablation outcome for suspected epicardial ventricular tachycardia in left ventricular nonischemic cardiomyopathy. J Am Coll Cardiol. 2009; 54 (9): 799-808.

15. Garcia FC, Bazan V, Zado ES, Ren JF, Marchlinski FE. Epicardial substrate and outcome with epicardial ablation of ventricular tachycardia in arrhythmogenic right ventricular cardiomyopathy/dysplasia. Circulation. 2009; 120 (5): 366-75.

16. Henz BD, do Nascimento TA, Dietrich CO Dalegrave C, Hernandes V, Mesas CE, et al. Simultaneous epicardial and endocardial substrate mapping and radiofrequency catheter ablation as first-line for ventricular tachycardia and frequent ICD shocks in chronic chagasic cardiomyopathy. J Interv Card Electrophysiol. 2009; 26 (3): 195-205.

17. Landymore RW, Gardner MA, McIntyre AJ, Barker RA. Surgical intervention for drug-resistant ventricular tachycardia. J Am Coll Cardiol. 1990; $16(1): 37-41$.

18. Niebauer MJ, Kirsh M, Kadish A, Calkins H, Morady F. Outcome of endocardial resection in 33 patients with coronary artery disease: correlation with ventricular tachycardia morphology. Am Heart J. 1992; 124 (6): 1500-6.

19. Josephson ME, Horowitz LN, Farshidi A, Spielman SR, Michelson EL, Greenspan AM. Recurrent sustained ventricular tachycardia: 4. pleomorphism. Circulation. 1979; 59 (3): 459-68.

20. Harris L, Downar E, Mickleborough L, Shaikh N, Parson I. Activation sequence of ventricular tachycardia: endocardial and epicardial mapping studies in the human ventricle. J Am Coll Cardiol. 1987; 10 (5): 1040-7.

21. Kramer JB, Saffitz JE, Witkowski FX, Corr PB. Intramural reentry as a mechanism of ventricular tachycardia during evolving canine myocardial infarction. Circ Res. 1985; 56 (5): 736-54.

22. Kimber SK, Downar E, Harris L, Langer G, Mickleborough LL, Masse S, et al. Mechanisms of spontaneous shift of surface electrocardiographic configuration during ventricular tachycardia. J Am Coll Cardiol. 1992; 20 (6): 1397-404.

23. Kuck KH, Schluter M, Kunze KP, Geiger M. Pleomorphic ventricular tachycardia: demonstration of conduction reversal within the reentry circuit. Pacing Clin Electrophysiol. 1989; 12 (7 pt 1): 1055-64.

24. Waspe LE, Brodman R, Kim SG, Matos JA, Johnston DR, Scavin GM, et al. Activation mapping in patients with coronary disease with multiple ventricular tachycardia configurations: occurrence and therapeutic implications of widely separate apparent sites of origin. J Am Coll Cardiol. 1985; 5 (5): 1075-86.

25. Garan H, Fallon T, Rosenthal S, Ruskin JN. Endocardial, intramural, and epicardial activation patterns during sustained monomorphic ventricular tachycardia in late canine myocardial infarction. Circ Res. 1987; 60 (6): 879-96.

26. Costeas C, Peters NS, Waldecker B, Ciaccio EJ, Wit AL, Coromilas J. Mechanisms causing sustained ventricular tachycardia with multiple QRS morphologies: results of mapping studies in the infarcted canine heart. Circulation. 1997; 96 (10): 3721-31.

27. Horowitz LH, Josephson ME, Harken AH. Epicardial and endocardial activation during sustained ventricular tachycardia in man. Circulation. 1980; 61 (6): 1227-38.

28. Kaltenbrunner W, Cardinal R, Dubuc M, Shenasa M, Nadeau R, Tremblay $\mathrm{G}$, et al. Epicardial and endocardial mapping of ventricular tachycardia in patients with myocardial infarction. Circulation. 1991; 84 (3): 1058-71. 